\title{
ARTIGOS
}

\section{AS HERESIAS DOS SÉCULOS XII E XIII (III).}

\author{
NACHMAN FALBEL \\ Do Departamento de História da Faculdade de Filoso- \\ fia, Letras e Ciências Humanas da Universidade de \\ São Paulo.
}

(Conclusẫo) .

$\mathrm{V}$

OS BEGUINOS. ticos.

E' a partir de 1317 que os beguinos foram tratados como heré-

A seita dos beguinos ou Pobres Irmãos da Penitência da Ordem de São Francisco declaravam aceitar a Terceira regra de São Francisco (1). A partir do ano 1315 se encontravam já suspeitos e perseguidos em Narbona, em Toulouse e Catalunha, onde um bom número foi aprisionado e queimado.

Os beguinos foram muito influenciados pelos escritos de Pedro João Olivi, originário de Sérigmam, perto de Béziers. Seus comentários sôbre o Apocalipse foram lidos em latim e língua vulgar. Também se dizia ser $\mathrm{o}$ autor de outros tratados que eram lidos entre os beguinos; um sôbre a pobreza, outro sôbre a mendicidade e ainda outro sôbre as dispensas religiosas.

Nasceu Olivi em 1248 ou 1249 e morreu em 1298.

No ano de 1319, em Avignon, oito mestres de Teologia examinaram o dito comentário do Apocalipse. Ao seu ver muitos artigos foram considerados heréticos, outros foram tachados de falsos. $O$ julgamento definitivo da obra não ficou nisto, pois, o Papa João XXII se reservou o direito de promulgar uma sentença final ulterior em 27 de setembro de 1322 (2).

A condenação solene da Apostilha de Olivi foi feita em consistório a 8 de fevereino de 1326 .

(1). - Pauperes de penitentia de Tertio Ordine Sancti Francisci.

(2). - Eubel, Bullarium Franciscanum, t. V, pág. 233, n. 483. 
Fenômeno conseqüente da reforma gregoriana e de tendência à vida apostólica promovido pelos pregadores ortodoxos e hereges, é o das beguinas (mulieres religiosae, beguinae, begginae). Sob a direção de uma mestra vivem vida comum, sem votos pròpriamente dito dentro de "côrtes de beguinas", que se dedicam à oração, ao trabalho manual, à assistência aos enfermos, ao cuidado dos cadáveres e à educação das crianças. Teria sido fundada por Santa Bega ( $\dagger$ 694) filha de Pepino, o Velho (de acôrdo com uma lenda do século XV), ou por obra do pregador penitencial Lamberto, le béque ( o gago) ou le béguin (1177) em Liège. Outros derivam o nome dos (Al-bigen-ses), caso êle não provenha do hábito "incolor" das mulheres $($ bège $=$ bege $)$. As beguinas apareceram pela primeira vez nos ambientes da bem aventurada Maria de Oignies $(\dagger 1213)$ em Nivelles, no Brabante meridional, pelo fim do século XII. Propagou-se em Liège e em outras cidades da Bélgica e dos Países-Baixos, da França e da Alemanha. Gregório IX baixou em seu favor um brevet de proteção (1233). Mas muitas beguinas deixaram-se influênciar pelas idéias panteístico-quietistas dos Irmãos do Livre Espírito e incorreram nas impressões da Inquisição de sorte que tôda associação foi desacreditada e o concílio de Viena de 1311 ordenou a sua supressão. Contudo João XXII permitiu ainda às beguinas ortodoxas a vida comum e o exercício de sua atividade caritativa. Alguns conventos de beguinas uniram-se à ordem Terceira de São Francisco ou de São Domingos. Os begardos (beguines, begines, begardos), associação masculina paralela à das beguinas, aparecem por volta de 1220 nos Países-Baixos. Atuavam na assistência aos enfermos e sepultamento dos mortos e tiveram difusão tão extensa, quanto as beguinas. Bem cêdo degeneraram e se tornaram suspeitos de heresia, de modo que desapareceram antes do século XVI.

No comentário ao Apocalipse Pedro João Olive combina os devaneios apocalípticos de Joaquim Flora com as elucubrações do frade menor Gérardo de Borgo San Donnino, expressas em 1254, nun opúsculo $O$ Evangelho Eterno. O sucesso de Pedro João Olivi entre os beguinos e os "espirituais" se deve ao fato de ter escrito uma síntese bem ordenada das teorias aceitas entre êles. Segundo Gebhart (3), Pedro João Olivi, foi castigado com moderação por vários Gerais da ordem, por Gerónimo de Ascoli, o futuro Nicolau IV, por Bonagracia, em Estrasburgo, depois em Avignon, por Arlotto de Prato em Paris, pela segunda vez em 1292 em Paris, devia explicar-se perante o capítulo geral presidido por Raimundo Gaufridi. Morreu tranqüilamente

(3). - GEBhaRT (Emílio). - La Italia mistica. Ed. Nova, Buenos Aires, 1943, pág. 172 . 
em Narbonne, em 1298, depois de uma edificante profissão de fé católica e um ato de submissão ao Papa Bonifácio VIII. Durante alguns anos o aniversário do dia de sua morte foi celebrado com grande devoção pelo clero e o povo de Provença. Mais tarde, durante o pontificado de João XXII, maltrataram e perseguiram os monges que se obstinavam em ler seus escritos. Foi acusado formalmente de heresia e desenterraram seu cadaver queimando-o (4). Beguinos e espirituais o adoravam como a um santo.

Pedro João Olivi havia escrito dois tratados, o De Paupere usu e o De Perfectione evangelica, que desapareceram e comentários sôbre - Gênese, os Salmos, os Provérbios, o Cântigo dos Cântigos, os Evangelhos e o Apocalipse; um tratado sôbre a Autoridade do Papa e do Concílio e uma exposição da Regra de São Fracisco, cujo manuscrito possuímos.

Seus pontos de vista são resumidos por Ângelo Clareno, na Historia Septem Tribulationum ordinis Minorum são claros; não concede a seus irmãos mais que o uso dos alimentos necessários para a vida de cada dia e os objetos, breviários ou vestimentas sagradas que servem para o ofício divino. Proíbe-os receber pelas sepulturas outorgadas nas igrejas dos Menores, e receber doações. $\mathrm{O}$ mais profundo de sua doutrina era, segundo seus censores e apologistas uma idéia joaquimita. Proclamava um estado futuro da Igreja, mais perfeito que o precedente, de que São Francisco era o percursor e cujo advento seria apressado pelas reformas monacais .

Nicolas Eymeric, escreveu a lista das heresias contidas nas obras de Pedro João Olivi, em seu Directorium Inquisitorium:

"A regra de São Francisco é verdadeiramente a lei evangélica. A lei dos franciscanos é reprovada pela Igreja carnal, como era a lei dos cristãos pela sinagoga. E' necessário que a Igreja carnal, para acabar de merccer a sua destruição condene a regra de São Francisco. A lei evangélica de São Francisco está chamada a prosperar entre os gregos, os judeus, os sarracenos e os tártaros, mais que na Igreja carnal dos latinos. Esta Igreja, que se chama universal, católica e militante não é mais que a Babilônia impura a grande pervertida, meretriz magna, que a simonia, o orgulho e todos os vícios precipitam no inferno. Corresponde aos doutores do Estado perfeito muito mais do que correspondeu antigamente aos apóstolos, abrir as portas espirituais da sabedoria cristã".

(4). - EHRLE (F.). - In "Archiv für Literatur und Kirchengeschichte", t. II, 1886, pág. 293, e t. III, 1887, pág. 443. 
Frei Ângelo foi perseguido e condenado à prisão perpetua, posto em liberdade em 1289 pelo Geral Raimundo Gaufridi; logo depois foi obrigado a refugiar-se, apesar de, sob o pontificado de Celestino $\mathrm{V}$ ter um curto repouso, em uma ilha do Adriático ou nas ermidas da campanha romana e do reino de Nápoles a fim de escapar a Bonifácio VIII. Morreu em 1337. Em1317,escreveu ao Papa João XXII uma ampla epístola apologética para defender a ortodoxia de seus irmãos; na mesma época, desde Avignon e depois desde os arredores de Roma, escreveu cartas aos espirituais espalhados por tôda a Itália, para encorajá-los em sua fé. São testemunhos preciosos os de Ângelo Clareno para a questão dos espirituais.

Apesar da Igreja, após ter se amainado a rebelião dos fraticellos, se mostrar mais indulgente com a memória de Pedro João Olivi (Sixto IV, Papa franciscano, permitiu a leitura de seus livros), sabemos a que excessos se haviam entregue os conventuais (que aceitaram a remodelação na regra franciscana) contra os discípulos diretos de Olivi. Conforme o livro das tribulações, um dêstes discípulos, Pôncio de Buontugato, que se recusou a entregar os escritos de seu mestre foi encarcerado em uma cela esperando a morte com "alma jubilosa e ardente de amor". A mesma sorte foi rese ${ }_{i}$ vada a Tomás de Casteldemilio. Outros, como Pedro de Macerata que estavam condenados foram libertados a tempo pelo Geral Raimundo Gaufridi. Pediram para ser enviados às missões do Oriente, convencidos de que encontrariam entre os sarracenos a misericórdia e a liberdade que já não esperavam de seus irmãos. Assim, entre os religiosos da Itália que pretendiam a perfeição absoluta e o risto da família franciscana, menos exigentes, mais razoáveis e satisfeitos, elegeu-se um caminho menos espinhoso para a salvação.

Assim, entre êsse desprendimento de tudo, é então muito simples, até entre um grande número de afiliados da Ordem Terceira, que se esforçam em escapar das obrigações de seu estado social e buscam no seio das cidades populosas a paz e o egoismo do claustro. O Papa franciscano Nicolau IV renovou em 1289, com a bula Supra Montem, a constituição dos Terciários ou dos "Irmãos da Penitência", cuja primeira regra era posterior cinco ou seis anos à morte de São Francisco.

Em 1290, com a bu!a Unigenitus, confirmava aos visitadores da ordem a vigilância dos afiliados aos quais, subtraidos à fiscalização de seus bispos, formavam uma espécie de instituição religiosa. Em cada comuna uma parte considerável da burguesia dependia, em virtude desta regra, dos chefes dos menores e, por conseguinte, da Santa Sé. Em 1291, com a bula Ad audientiam, dirigida ao bispo de Florença, Nicolau IV nos informa sôbre a crise que se produziu entre 
os Terciários: aquêles que, rebeldes à constituição da bula Supra Montem, se estreitaram ao redor do bispo e receberam em recompensa por seu apêgo a velha disciplina os privilégios, breviários, os móveis e os bens da antiga confraria. O Papa toma então a defe:a dos mais dóceis a Santa Sé, os quais aos olhos do bispo e do clero paroquial de Florença são verdadeiros apóstatas. Esta resistência do episcopado italiano às reformas de Nicolau IV é um dos numerosos incidentes da luta da Igreja secular contra as ordens mendicantes. Mas no curso desta crise se nota um conflito menos grave entre a sociedade civil e os Irmãos da Penitência. As relações entre o Estado e esta vasta comunidade eram difíceis. Desde as origens, os Terciários se subtrairam ao serviço militar, do dever feudal, de exercer cargos públicos. Os papas estão constantemente ocupados em livrá-los das exigências da lei comunal. Gregório IX determina os casos estritos nos quais podem prestar juramento em justiça e concorrer aos compromissos solenes de suas cidades. Nicolau IV confirma, "por indulgencia da sede apostólica" exceções à regra geral da abstenção civil. Renova, ademais, o privilégio dado aos Terciários de dispor de seus bens em favor dos pobres ou da Igreja a exceção de suas famílias ou do Estado, aos quais êsses cristãos extrem stas recusam o pão e o impôsto, em nome da pobreza- evangélica (5).

Os beguinos viviam nas cidades e nos burgos em pequenas "casas da pobreza". Em dias de festas e aos domingos, os beguinos que habitavam em comum se reuniam com seus familiares ou amigos. Liam juntos os opúsculos ligados à sua doutrina, que tratavam dos mandamentos, dos artigos da fé e as lendas de santos.

Entre êles alguns mendigavam de porta em porta a fim de cumprir a pobreza evangélica, outros trabalhavam e ganhavam, mas levando sempre uma vida paupérrima.

Os beguinos sustentavam que Jesus e seus apóstolos em sua vida mortal, não possuiram nada, nem em particular e nem em comum, pois êles eram nesse mundo pobres perfeitos.

Afirmavam também que a regra de São Francisco é a mesma regra que Jesus Cristo observou nesse mundo e legou a seus apóstolos.

O que disse São Francisco aos seus irmãos no tocante à pobreza evangélica deve-se interpretar de tal modo de que os seus apóstolos ou melhor os que professam a dita regra não possam nada possuir nem em particular nem em comum. Mas sòmente o necessário à vida, fa-

(5). - Esta descrição foi feita segundo Gebhart, La Itália Mistica, que por sua vez se baseia em K. Müller, Die Anfánge des Minoritem orden und der Bussbruderschaften, cap. III. 
zendo sòmente o uso "pobre" (6) que frisa a indigência e prescreve todo o supérfluo.

Para êles, São Francisco foi após Jesus e os apóstolos o principal e o maior observador da vida e da regra evangélica; êle foi o renovador nesta sexta idade da Igreja que é a nossa época. Que a Regra é o mesmo que o Evangelho de Cristo, e quem a combate, portanto combate o Evangelho e portanto não passa de um herético. Assim como o Papa e nenhum outro podem modificar o Evangelho, do mesmo modo ninguém pode modificar a regra de São Francisco, nem ajuntar ou suprimir. Portanto, o Papa não tem o direito da anular a dita regra evangélica de São Francisco que não é outra senão a ordem evangélica. Isto também é valido para a regra e a terceira ordem de São Francisco.

Um Papa ou Concílio geral não podem anular ou contradizer as aprovações, decisões ou ordenações confirmadas por antecessores seus, portanto as duas regras de São Francisco confirmadas pelos pontífices romanos como tôdas as regras não podem ser anuladas por nenhum Papa nem mesmo por Concílio geral. Caso o fizer, ninguém deverá obedecê-lo, mesmo sob pena de excomunhão.

O Papa não pode dispensar alguém dos votos feitos à regra de São Francisco, isto é, a castidade, pobreza e obediência; e mormente do voto de pobreza feito a Deus, quando êste voto foi simples e não solene, a pessoa que fêz um voto de pobreza terá de observá-lo, para sempre, pois a dispensa implicará em descer de um grau de virtude e de perfeição mais elevado a um grau baixo e inferior, e que o Papa não pode usar de seu poder senão para construir e não destruir. $O$ Papa não tem o direito de editar uma bula ou decretal, permitindo os Frades Menores, ou dispensando-os de conservar, com previsão ao futuro, nos silos e celeiros, o grão e o vinho para o seu uso e alimentação, pois isto é contrário a regra evangélica de São Francisco, e por consequiência ao Evangelho de Cristo.

Nicolau III aprovou pela bula Exiit qui seminat, e levou a abdicação de tôda a propriedade:

"O Cristo dizia, traçou a via da perfeição, a ensinou oralmente e a pôs em prática".

A propriedade dos imóveis adquiridos pelos menores ou recebidos por doação, bem como os objetos móveis eram propriedades da

(6) . - Pedro João Olivi compôs em 1279, um tratado sốbre o "uso pobre" que T. Ehrle publicou no Archiv für literatur und Kirchengeschichte, t. III, 1887, págs. 507-517. 
Santa Sé. Clemente V' no Concílio de Viena, confirma a decisão de seu precursor pela bula Exivi de Paradiso.

O Papa João XXII, pela bula Quorundam (7) permite aos Frades Menores, ao arbítrio dos superiores da Ordem, de manter reservas de grãos e vinho, se coloca em oposição a pobreza evangélica e portanto ao Evangelho de Cristo. Ele caiu na heresia enquanto perseverar, e perde devido a isto o poder papal de ligar e dissolver, bem como os outros poderes. Também os Frades Menores que por sua instância provocaram tal constituição ou bula, que aprovaram, a aceitaram e fizeram uso dela, são declarados hereticos (8). O Papa não tem o direito de dispensar, contràriamente à regra de São Francisco, no que concerne ao tamanho e qualidade do habito dos Frades Menores, onde todo o supérfluo deve ser banido; nisto não se deve seguí-lo bem como em tudo que é contrário à dita regra. Os prelados saídos da Ordem de São Francisco, devem continuar mantendo a perfeição evangélica, segundo a regra (9).

Os quatros heréticos condenados em Marselha em 1318 o foram pelo inquisidor Michel Lemoine, franciscano também, que João XXII designou para perseguir os espirituais. Em 6 de novembro de 1317, êles o foram por terem entendido do seu dever manter a pureza, a verdade e a pobreza da regra de São Francisco, e também por não terem aceito abrandamento desta regra e não terem aceitado a dispensa concedida pelo Papa neste ponto e, portanto, se negado à obediência papal; êles foram condenados injustamente e pela defesa da

(7). -7 de outubro de 1317 (Eubel, Bullarium Franciscanum, t. V, págs. 128-130): Na bula Quorundam há referência à vestimenta dos frades. E' proibido aos frades os hábitos curtos, estreitos $\mathrm{c}$ remendados do tipo que os espirituais usavam. Denifle e Chatelain, Chartularium Universitates Parisienses, t. II, pág. 215, n. $^{\circ} 760$, publicaram uma consulta de treze teólogos relativa às objeções formuladas pelos espirituais contra a bula Quorundam.

(8). - Trata-se dos conventuais da Ordem Franciscana. Foi por instigação do ministro geral Michel de Cesena e dos chefes dos conventuais que João XXII dirimiu o litígio que clividiu depois durante muito tempo a ordem dos Menores em duas facções inimigas. Desde 1316 êle pediu insistentemente que se pusesse um fim às extravagâncias dos espirituais nos conventos de Narbonne e de Béziers. Eles adotam costumes estranhos, êles praticam um ascetismo rigoroso, êles expulsam os conventuais que habitam lá, se declaram independentes de seus superiores (Histoire literaire de la France, t. XXXIV, pág. 427).

(9). - A Santa Sé considerava de fato os cardeais e os bispos saídos da ordem dos Menores como desligados do voto da pobreza, pois ela lhes dava e autorizava o direito de possuir numerosos benefícios. João XXII orientou o espiritual Ubertino da Casale ao entrar no mosteiro beneditino da Sant Pierre, em Gembloux, apesar dos estatutos e costumes da ordem franciscana, sem dúvida, a fim de pôr um têrmo às discussōes que o agitador suscitava entre os irmãos pela publicação de seu livro $A$ árvoré da vida (bula de 1-10-1317). Eubel, Bullarium, Franciscanum, t. V, n. ${ }^{\circ} 287$, pág. 127). Isto vem mostrar que a mudança de ordem de um frade franciscano não o desliga do voto de pobreza. 
regra evangélica. Portanto, não são heréticos, mas católicos e mártires gloriosos, "e por isso implramos por êles orações a Deus." E para muitos beguinos, Cristo foi novamente crucificado na pessoa dos quatro frades menores, como se fôsse sôbre os quatro braços da cruz; nêles a pobreza de Cristo e sua vida foram condenados. Se o Papa ordenou e àprovou tal condenação feita por seu Inquisidor, êle mesmo é o herético e o maior de todos, pois, como chefe da Igreja, deveria assumir a defesa da perfeição evangélica. Daí ter êle perdido o poder pontifical e não ser êle mais Papa entre os fiéis, que não lhe devem mais obediência: a sede é considerada vacante. Um certo número de beguinos, foram condenados após o ano de 1318 (10), como heréticos pelos prelados e inquisidores na província de Narbonne, em Narbonne, Capestang, em Béziers, em Lodève, na diocese de Agde, em Lunel: Eles tinham aos quatro frades menores como santos mártires. Os nomes dêstes menores nos foram conservados. Eles se chamavam Jean Barrou (Barravi). Déodat Michel, Guithem Sancton (Sanctonis), Pons Roche (Rocha), segundo a sentença formulada por Michel Lemoine (11). Aos seus olhos o ensinamento de Pedro João Olivi é a verdadeira doutrina católica, e a Igreja carnal, isto é a Igreja Romana, isto é, a Babilônia, a grande prostituta será destruida e demolida,

"sicut olim destructa fuit synagoga Judeorum, incipiente ecclesia primitiva".

Os prelados e religiosos que usam roupagens supérfluas e ricas, agem contràriamente à perfeição evangélica, e aos preceitos de Cristo, mas em favor do Anti-Cristo; êles e os clérigos que ostentam pompa são da família do Anti-Cristo.

Outro aspecto da doutrina dos beguinos é o da aceitação da afirmação de Pedro João Olivi de que Cristo vivia quando foi crucificado e sua alma residia realmente em seu corpo. O Concílio de Viena ( 6 de maio de 1312) decretou, contràriamente a Pedro João Olivi, acêrca da morte de Jesus:

\footnotetext{
"Nós declaramos que o dito apóstolo e Evangelista João apresentou os fatos com exatidão quando êle diz que o Cristo já estava
}

(10). - Ãngelo Clareno, na sua história Septem Tribulationum ordinis minorum (ed. F. Ehrle, in Archiv für Literatur-und Kirchengeschichte, t. II, 1886, págs. 142-147), narra as perseguições injustas aos beguinos feitas pelos prelados e inquisidores da heresia, após o ano de $1318 \mathrm{em}$ muitos lugares da província de Narbona, em Narbona, em Capestang em Béziers, em Lodève, na diocese de Agde, em Lunel, em Marselha e na Catalunha. Quatro foram condenados e qucimados em Marselha, 7 de maio de 1318, além de outros tantos condenados a diversas penas.

(11). - Eubel, Bullarium Franciscanum, t. V, pág. 133. 
morto no momento em que um dos soldados abriu o seu lado com um golpe de lança" (12).

Pedro João Olivi é considerado por êles como sendo aquêle anjo do Apocalipse, cap. X, de uma maneira espiritual, que na sua face era como o sol e que tinha um livro aberto em sua mão. Entre todos os doutores, é a êle que se manifestou a verdade de Cristo e o entendimento do livro da Apocalipse. E se o Papa condenou a doutrina, e os escritos do frade Pedro João Olivi, será êle considerado herét co, pois condenou a vida e a doutrina de Cristo (13).

Assim sendo, mesmo que sejam excomungados, os beguinos não obedecerão e não se considerarão como tal.

Ao fim da sexta idade da Igreja na qual nós estamos e que $\infty$ meçou com São Francisco a dita Igreja carna!, Babilônia, a grande prostituta, será rejeitada por Cristo, como foi outrora a sinagoga dos judeus. Estes crucificaram a Cristo a Igreja carnal, crucifica e persegue a vida de Cristo na pessoa dos que se denominaram Pobres Espirituais, da ordem de São Francisco (quo vocant pauperes et spirituales ordinis sancti Francisci).

$\mathrm{E}$ assim, do mesmo modo que após rejeitar a sinagoga dos judeus, Cristo escolheu um pequeno número de homens que na primeira idade da Igreja, fundavam a Igreja primitiva, assim, após a rejeção e a destruição da Igreja romana carnal, na sexta idade da Igreja, estará um pequeno número de eleitos, espirituais, pobres evangélicos, dos quais a maioria pertencerão as duas ordens de São Francisco, à primeira e à Terceira. E' por meio dêles que será estabelecida a Igr'ja espiritual, que será humilde e boa, na setima e última idade da Igreja que começará com a morte de Anti-Cristo. Tôdas as ordens religiosas serão destruídas pelas perseguições do Anti-Cristo com excessão da ordem de São Francisco. E ainda distingüirão na ordem três partes: a primeira constituída do que êles chamam, a massa da ordem. A segunda compreende os fraticellos da Itália. Os fraticellos eram espirituais que haviam formado comunidades independentes da ordem mesma dos Frades Menores sob a cobertura dos privi'égios concedidos em 1294, por iCelestino V, mas revogados por Bonifácio VIII. Habitavam mais comumente na Itália Meridional. A terceira se compõe dos irmãos que chamamos espirituais e que observam em sua pureza

(12). - Eubel, Bullarium Franciscanum, t. V, pág. 86.

(13). - Em seguida a um inquérito feito pelo ministro geral dos Menores, o capítulo reunido em Marselha no ano de 1319 autorizou a condenação dos escritos de Pedro João Olivi como hcréticos. F. Ehrle, Petrus Johannes Olivi sein Lcben und seine Scleriften, no "Archiv füł Literatur Kirchengeschichte", t. III, ano 1887, , pág. 451 . 
- espírito da regra de São Francisco, assim como os irmãos da Terceira ordem que aderem a suas doutrinas. Os dois grupos serão destruidos, o terceiro durará até o fim do mundo: esta é dizem êles, a promessa feita por Deus a São Francisco.

O Espírito Santo, será distribuido abundantemente sôbre os e'eitos espirituais e evangélicos como no dia de Pentecostes sôbre os apóstolos discípulos de Cristo, na primitiva Igreja. Eles ensinam que haverá dois Anti-Cristos: um espiritual ou simbólico, outro, o verdadeiro e principal; o primeiro preparará os caminhos do segundo. O primeiro Anti-Cristo, é o Papa (isto é, o Papa João XXII), sob o qual terão lugar as suas próprias perseguições e condenações. A época da vinda do grande Anti-Cristo, do início de sua pregação, de sua morte, terminará segundo uns em 1325, segundo outros em 1330, e segundo outros o mais tardar em 1335. Estes homens espirituais que são chamados evangélicos que estabelecerão a nova Igreja, pregarão às doze tribus de Israel; êles converterão doze mil homens de cada tribo, ou seja, 144 mil homens, esta será a milícia marcada pelo anjo levando o signo do Deus vivo, isto é, o santo Francisoo que portava a stigmata de Cristo. Esta milícia combaterá contra o Anti-Cristo e o matará antes da vinda de Elias e Enoque.

Haverá uma sucessão de grandes guerras e uma grande carnificina de povos cristãos, um número considerável de sêres humanos tombará durante esta guerra. Após a destruição desta Igreja carnal, virão os sarracenos e ocuparão a terra dos cristãos, tudo de acôrdo com a revelação feita a Pedro João Olivi, em Narbonne.

Com a destruição restarão doze homens espirituais que converterão o mundo à verdadeira fé de Cristo; todo, o mundo será bom e misericordioso, os homens não serão mais maliciosos e serão sem pecado, todos os bens, serão de uso comum (et omnia erunt communia quoad usum); ninguém ofenderá ao próximo e o levará ao pecado, onde, reinará a caridade entre os homens e haverá um rebanho e um pastor. De acôrdo com alguns este estado durará cem anos; depois a caridade (o amor) diminuirá, a malícia se introduzirá paulatinamente entre os homens e chegará a tais excessos que Cristo virá forçosamente para o julgamento geral.

As invectivas contra o Papa são violentas: símbolo do Anti-Cristo, seu percursor e preparador de seu caminho, o chamam de lôbo rapaz que deve ser evitado pelos fiéis; de profeta tortuoso e cego, grão-sacerdote Caifás, que condenou a Cristo; javali da floresta, bêsta feroz que destrói o muro da Igreja de Deus para deixá-la exposta aos cães e porcos, isto é, aos que pisoteiam a perfeição da vida evangélica; herético dos piores que já houveram e que levou a Igreja de Deus a ser uma sinagoga do diabo. 
A perseguição contra os beguinos foi ocasionada pela publicação da bula Sancta Romana (30 de dezembro de 1317).

Quanto a Inquisição contra tais heréticos, começou ela na província de Narbonne em $1318 \mathrm{e}$ em Toulouse, em Pamiers no ano de 1322, quando João XXII ordenou em 26 de fevereiro dêste ano ao bispo de Pamiers que investigasse os beguinos. O próprio Bernard Gui, que nos fornéceu esta descrição dos beguinos atuou contra êles em 1322 e em 1323 comc êle própio testemunha em seu livro das Sentenças (14). De acôrdo com Wadding (15), os inquisidores franciscanos condenaram cento e quatorze à fogueira em 1323. M. Tanon (16), afirma que nós não conhecemos senão que uma pequena parte das execuções que tiveram lugar. Mosheim, em sua obra $D e$ Begardis et Beguinabus connmentaritis, revelou, em um julgamento da Inquisição, de Carcassonne, uma lista de 113 supliciados, a partir de 1318 .

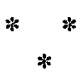

Apêndice n. 4.

Dois caracteres da doutrina dos Beguinos na Practica Inquisitionis heretice pravitatis, de Bernardo Guidonis ("Les classiques de l'histoire de France au Moyen Âge", Paris, 1964).

"habere et tenere plures errores ac opiniones erroneas, extolentes se adversus Romanam ecclesiam et apostolicam sedem ac contra primatum sedis ejusdem et contra apostolicam potestatem domini pape ac prelatorum ecclesie Romae", p. 110.

"Notandum quoque est quod intereos sunt aliqui qui publice mendicant hostiatim, quia, ut, dicunt, noverunt evangélicam paupertatem: Sunt et alii qui non mendicant, publice, set aliqua suis membros operartur et lucrantur et pauperam vitam docunt", p. 116.

\section{CONCLUSÕES.}

Vimos na Introdução de nosso trabalho que as heresias dos séculos XII e XIII tinham uma profunda base popular decorrente de um processo que vinha atterando paulatinamente as bases tradicionalistas, mais estáveis, da sociedade medieval até ao ano 1000 , configurando-a com novos elementos anteriormente inexistentes.

(14). - Limbcrch, Historia Inquisitionis, págs. 393-394.

(15). - Annales Minorum, t. VI (Roma, 1730), pág. 296, n. ${ }^{\circ} 44$, ann. 1317.

(16). - Tanon (M.). -- Histoire des tribunaux de Inquisition, pág. 34. 
Apontamos o crescimento demográfico, o impulso mercantil renovado, a aglomeração na urbe com sua nova divisão social, como fatôres que atuaram para tal transformação.

Por outro lado, sob o aspecto das idéias, assistimos a determinado impacto sofrido pela camada ilustrada, causado pela introdução do pensamento aristotélico e sua interpretação arábico-hebráica no mundo latino, que forneceu alguns elementos teóricos para a formulação da heresia.

Com essa expansão social e os novos elementos naturais, se dá o crescimento do individualismo religioso, típico dos séculos XII e XIII. A religiosidade desta época foge dos padrões oficiais, porque tudo leva à busca de novas interpretações. Não é por acaso que surgem as ordens religiosas neste período histórico, com personalidades como as de São Francisco de Assis e São Domingos. Pois atrás de tudo isto podemos ver o profundo abismo que começa a se abrir e a separar a religião oficial ditada por seus representantes e a religiosidade popular que emana de novas circunstâncias.

A Igreja da época é incapaz de fazer frente à onda crescente do anti-sarcedotalismo que caracteriza esta nova religiosidade, que parece ansiar por uma religião mais humana, mais próxima ao palpitar do coração popular. Até no repentino despertar para a adoração da Virgem nessa época podemos ver um traço de humanização inspirado num cristianismo popular.

A Igreja da época, dominada por canonistas e administradores de talento, devotada à criação de um ensino e complexo corpo político, jurídico e financeiro, no que implicava fazer acôrdos, assumir compromissos e fazer concessões com reis e imperadores, era incapaz de fazer frente às novas exigências religiosas. Mesmo Inocêncio III, ou Gregório IX, que se aproximaram do nôvo espírito de religiosidade, estavam mais ocupados com o mundo legalístico, político e diplomático do corpo ec'esiástico para darem de seu tempo a compreensão de tal fenômeno. Não é que tal papado houvesse abandonado os ideais da reforma gregoriana, mas outrossim, se preosupavam com o aspecto mais palpável desta reforma: a fortificação e a independência da Igreja do poder laico. Também a ordem monástica tinha perdido sua austeridade de conduta e se encontrava desprestigiada por frequientes escândalos e por sua vida clerical.

Daí, a aspiração das heresias, em oposição a uma Igreja carnal, descreverem um futuro em que reinará uma Igreja espiritual, desvinculada de todo bem terreno, ao seu ver a verdadeira Igreja de Cristo e seus Apóstolos. Trata-se do ideal de uma Igreja Santa, com um sacerdócio purificado, vivendo a pobreza evangélica.

Podemos concluir que o Evangelho Eterno, a última idade da Igreja e tudo que é pré-anunciado no Apocalipse, é parte da visão 
herética e comum à maioria das heresias da época. A pobreza evangélica, a volta à simplicidade do Cristianismo primitivo também é uma idéia central e marcante destas heresias, de valdenses e beguinos, ao ponto da idéia ser declarada herética pelo papado do século XIV. Poderiamos julgar o pronunciamento de Pascoal II (1099-1116), ardoroso partidário da reforma gregoriana, ao encerrar a controvérsia das investiduras, abandonando a riqueza e o poder da Igreja germânica às mãos do rei germano, como precursora da doutrina da pobreza apostólica da Igreja. Também laicos devotos não deixavam de criticar em têrmos ásperos o papado e o sacerdócio, sem estarem filiados à heresia. Vejamos como se expressa um homem como Walter von den Vogelweide (17):

\author{
St. Peter chair is filled to-day as well \\ As when 'twas fould by Gerbet sorcery; \\ For he consigned himself alone hell, \\ While this pope thither drags all Christentie. \\ Whi are the chastisements of Heaven de layed? \\ How long wilt thou in slumber lie, $O$ Lord? \\ Thy work is hindered and Thy word ganisaid, \\ Thy treasurer steals the wcalth that Thou hast stored. \\ Thy ministers rob here and murder there. \\ And o'er Thy sheep a wolf has shepherds care.
}

No fundo a heresia reformula a missão espiritual da Igreja após muitos séculos de esforços por parte de seus representantes para fortificarem a concepção de que todo poder emana dela. Esta total volta a uma religião puramente espiritual, é, talvez, a maior contribuição do pensamento herético nos séculos XII e XIII. Porém sua idéia central que é sua fôrça, não deixa de encerrar sua debilidade. A aspiração de tornar a uma Igreja espiritual estava fora do tempo presente (é sintomático que ela transfira a realização de suas concepções para um futuro distante, frequientemente envolto de mistérios apocalípticos). Quando o Papa-eremita Celestino V é eleito e se espera que êle consiga avançar no tempo, realizando parte das aspirações heréticas, êle se vê dominado por seus conselheiros, aturdido pelo aparato material da Igreja, massacrado por uma função que não é mais de santos e puros. As chaves de São Pedro eram pesadas em demasia para o Papa-eremita, que acaba se conduzindo como uma figura estranha e pequena, perdida no imenso palácio papal. A rea!idade tinha vencido êsse tipo de Cristianismo ingênuo e puro, e a História da Igreja se

(17). - Extraído de The Medieval World. 300-1300. Ed. Norman F. Cantor, Colúmbia University, 1963, pág. 261. 
mostrava irreversível. Quem poderia, agora, construir a Cidade Celestial, a ambicionada Civitas Dei agostiniana?

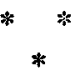

\section{BIBLIOGRAFIA GERAL.}

DAVIS (Georgene W.) - The Inquisition at Albi (1299-1300). New York, CoIumbia Press, 1948.

DOLLINGER (J.). - Beitrage zur sektengeschichte des Mittelalters. V. 2, 1890.

GEBHART (E.). - La Italia mistica. Buenos Aires, Ed. Nueva Buenos Aires, 1943.

GRUNDMANN (H.). - Religiose bervegungen im Mittelalier, 1935.

HAVET (Julien). - L'heresie et le bras séculier au moyen âge jusqu'au Ie Xlie. siècle. In "B. de l'Ecole de Chartes", t. XLI, 1880.

HASKINS (C. H.). - The Renaissance of the twelfih century. Cambridge, 1927.

LEA (H. Ch.). - The Inquisition of the middle ages. London, Eyre and Spottiswoode, 1963.

LIMBORCH. - Historia Inquisitionis. Ed. Henricum Wetstenium, Amstelodami, 1692 .

MAISONNeUVE (H.). - Etudes sur les origines de l'Inquisition. Paris, Lib. Philosophique J. Vrin, 1942.

MANSI (J.D.). - Sacra Conciliorum Decreta. Florence-Venise, 1759-1798. Paris, 1901.

PLRRIN (Ch. Edmond). - L'église et la vie religieuse de 1305-1378. Paris, Centre de Documentation Universitaire, s.d.p. (mimeogafado).

PELAYO (M. M.). - Historia de los heterodoxos. Madrid, B. A. C., 1965, 2 vols. TOCCO (F.). - L'eresia nel Medio Evo. Florença, 1884.

TUECHLE (H.) \& BIHLMEYER (K.). - História da Igreja. São Paulo, ed. Paulinas, 1964, 3 vols.

VOLPE (G.). - Movimenti religiosi e sette ercticali nella societá medievale italiana. Florença, 1926.

FONTES IMPRESSAS.

BERNARDUS GUIDONES (Bernard Gui). - Pratica inquisitionis haereticae pravitates. Paris, Ed. Les Class. de l'Histoi:e de France au Moyen Âge, 1964.

GiOACCHINO DA FIORE. - Tractatus super quatuor Evangelia. Roma Istituto Storico Italiano, 1930.

INNOCENTIUS III. - Epistolas. In M. P. L., vol. CCXIV-CCXVI.

MONETA DE CREMONA. - Summa contra katharos ct valdenses, Roma, Ed. Ricchini, 1743. 
NICOLAS EYMERIC. - Directorium inquisitorum. Romae; Ed. F. Pegna, 1578. OTTO DE FREISINGEN. - Chronicon Frederici $I$, in M. G. H., Script, vol. $\mathrm{XX}$.

PIERRE DES VAUX-CERNAY. - Historia Albigenses. Paris, Ed. Guebin et Lyon, 1926.

SALIMBENE. - Chronica, M. G. H., Script., t. XXXII, Hannover, 1905.

SÃo BERNARDO. - Carta 241, in M. P. L., vol. CLXXXII, col. 434.

\section{ALBIGENSES OU CATHAROS.}

AEGERTER (E.). - Les héresies du moyen âge. Paris, Ed. Lib. Ernest Leroux, 1939.

BELPERRON (P.). - La croisade contre les Albigeois, 1209-1229. Paris, 1942.

CHANSON de la Croisade Albigeoise. Paris, Les Classiques de l'Histoire de France au Moyen Âge, 1931.

DOUDAINE (A). - Un traité neomanicheen du XIIIe siècle. Roma, 1939.

DOUAIS (C.). - Les albigeois, leurs origines, Paris, 1879.

DOUAIS (C.). - L'Inquisition, ses origines et sa procedure. Paris, 1906.

GUIRAUD (J.). - Histoire de l'Inquisition au. Moyen Age, I. - Chatares et Vaudois. Paris, 1935.

GUIRAUD (J.). - Le consolamentum cathare, in "Revue des Questions Hsitoriques", t. XXV, 1904.

HOLMES (E.). - The Albigensian or Catharist heresy. London, 1925.

LEA (H. Ch.). - A history of the Inquisition of the Middle Age.s New Ylork, 1888,3 vol.

LUCHAIRE (A.). - Innocent III, t. II: La croisade des Albigeois. Paris, 1911.

ROCHÉ (D.). - Le catharisme. Toulouse, 1947.

ROCHÉ (D.). - L'Église romaine et les cathares albigeois. Paris, 1957.

RUNCIMAN (S.). - Le manicheisme médiúval. Roma, 1953.

\section{VALDENSES.}

COMBO (E.). - Storia dei valdesi. Torre Pellice, 1935.

DAVIDSON (S. E.). - Forerustners of S. Francis and other studies. London, 1928.

GAY (T.). - Histoire des Vaudois. Paris, 1912.

GONNET (G.). - Il valdismo mediezale. Torre Pellice, 1942.

GONNET (G.). - Fonti per la storia del valdesismo medisvale. Roma, 1951.

GONNET (G.) \& HUGON (A. A.). - Bibliografia valdese. Torre Pellice, 1954.

THOUZELLIER (C.). - Catharisme et Valdeisme en Languedoc à la fin du XIIe, et au début du XIIIe. siècle. Paris, 1966.

PSEUDO-APÓSTOLOS.

( $E$ outras heresias mencionadas na introdução).

KERAMP (J.). - Miscellanea Ehrle. Roma, 1924.

MOR (W.). - Annales Universitates Saravienses, 1954. 
TOCCO (F.). - Gli Apostolici e fra Dolcino. In "Archivo Storico Italiano", serie V, t. XIX, 1897.

TOCCO (F.). Guglielma boema e $i$ Guglielmiti. Roma, 1901.

JOAQUIM DE FLORA.

BONDATTI (Guido). - Gioachnismo e Francescanesimo nel Dugento. Assisi, 1924.

BUONAIUTI (E.). - Introduzione ao Tractatus super quator Evangelia. Roma, 1930.

DENIFLE (F.). Das Evangelium aeternum und die Comission zur Anagni. In "Archiv für Literatur und Kirchengeschichte". T. I, 1885.

\section{BEGUINOS.}

ALLARD (Paul). - Saint François d'Assise et la féodalité. In "Revue des Questions Historiques", t. XLVIII, 1890, p. 567-576.

CONGAR (Y.). - Aspects ecclesiologiques de la querelle entre mendiants et seculiers dans la seconde moitié du XIIIe. siècle et le début du XIVe. In "Arch. d'Hist. Doctrinale et Litteraire du Moyn Âge", XXVIII, 1961, p. 35-151.

EHRLE (F.). - Petrus Johannes Olivi, sein Leben und seine schriften. In "Arch. f. Literatur und Kirchengeschichte", t. III, ann. 1887 .

GREVEN (J.). - Die anfange des Beginen, 1912.

MARTI (J. M.) \& POU (O. F. M.). - Visionarios, Beguinos e Fraticellos catalanies (séc.XIII-XV), Vich, 1930.

LAMBERT (D.). - Franciscan poverty. The doctrine of the absolute poverty of Christ and the Apostles in the Franciscan Order. London, 1961.

MOSHEIM. - De Begardis et Beguinabus commentarius. Leipzig, 1790.

WADDING (L.). - Annales Minorum, t. VI. Roma, 1730.

ZANONI (L.). -Gli Umiliati nei loro rapporti con l'eresia. Milano, 1911. 